\title{
Mean Residence Time to Last Nonzero Concentration by Intravascular Dose
}

National Cancer Institute

\section{Source}

National Cancer Institute. Mean Residence Time to Last Nonzero Concentration by

Intravascular Dose. NCI Thesaurus. Code C121137.

Mean residence time (MRT) from the time of dosing to the time of the last measurable concentration, for a substance administered by intravascular dosing. (CDISC) 